\title{
Igreja, ditadura e livre comércio: as relações entre Brasil e Reino Unido durante o Regime Militar ${ }^{1}$
}

\author{
Church, dictatorship and free trade: \\ relations between Brazil and the United Kingdom \\ during the military regime
}

Graham Gerald McGeoch

Wanderley Pereira da Rosa

\section{Resumo}

A ditatura militar e seu legado ganharam novas pesquisas no Brasil e no exterior com a documentação disponibilizada ao público pela Comissão Nacional da Verdade (2014). Este artigo se propõe investigar a colaboração do governo britânico, através do seu Ministério das Relações Exteriores e de seus serviços de inteligência, com o regime militar brasileiro, inaugurado com o golpe de 1964. Essa colaboração, jamais reconhecida, visava preservar e incrementar o livre comércio entre as duas nações. Paralelamente, as igrejas nacionais britânicas (da Inglaterra e Escócia), bem como a imprensa e a sociedade civil, pressionavam o governo de seu país por um posicionamento firme frente às denúncias de tortura, violações dos direitos humanos e prisões contra dissidentes políticos em curso no Brasil. A pressão exercida pelas igrejas britânicas foi municiada pela intensa troca de informações com igrejas e lideranças eclesiásticas brasileiras no âmbito do movimento ecumênico. A baliza principal desta pesquisa é a farta documentação disponibilizada pelo Relatório Final da Comissão Nacional da Verdade.

\footnotetext{
${ }^{1}$ Este artigo é fruto de uma pesquisa preliminar apresentada no $3^{\text {a }}$ Congresso internacional da Faculdade EST, em 2016, agora ampliada: McGEOCH, G. G., Para inglês ver? Relações IgrejaEstado entre o Brasil e o Reino Unido (1964-1985), p. 470-481.
} 
Palavras-chave: Comissão Nacional da Verdade (CNV). Governo Militar. Brasil. Reino Unido. Relações Igreja-Estado.

\begin{abstract}
The military dictatorship and its legacy gained new research interest in Brazil and outside Brazil with the documentation of the National Truth Commission (2014) made available to the public. This article aims to investigate the collaboration of the British government, through its Foreign and Commonwealth Office and its intelligence services, with the Brazilian military regime, inaugurated with the 1964 coup. This collaboration, never recognized, aimed to preserve and increase free trade between the two nations. At the same time, the British national churches (of England and Scotland), as well as the press and civil society, were pressuring the government of their country to take a firm stand against allegations of torture, human rights violations and arrests of political dissidents in Brazil. The pressure exerted by British churches was fueled by the intense exchange of information with Brazilian churches and ecclesiastical leaders within the scope of the ecumenical movement. The main source of this research is the abundant documentation made available by the Final Report of the National Truth Commission.
\end{abstract}

Keywords: National Truth Commission (CNV). Military Government. Brazil. United Kingdom. Church-State Relations.

\title{
Introdução
}

Desde a publicação do Relatório Final da Comissão Nacional da Verdade (CNV) em 2014, as relações entre o governo militar do Brasil e o governo democrático do Reino Unido têm ganhado súbito interesse por parte dos parlamentares, da mídia e da sociedade civil. O Relatório Final da CNV assinalou a "colaboração britânica" no uso da tortura pelo regime militar brasileiro.

Logicamente, o Relatório Final limitou-se a identificar a relação entre o Estado brasileiro e o Estado britânico, particularmente o papel do Foreign and Commonwealth Office (Ministério de Relações Exteriores do Governo Britânico) e do Serviço de Inteligência Britânica. Também não passa 
despercebida a visita de Estado da Rainha Elizabeth II em 1968 - em plena ditadura militar - ao Brasil e a visita de Estado do Presidente Geisel em 1976 como chefe de Estado de uma ditadura com crescentes evidências de abusos de direitos humanos - ao Reino Unido. Documentos dos arquivos parlamentares britânicos mostram que as duas visitas foram vistas como oportunidades de promover tanto a reforma democrática no Brasil quanto acordos comerciais entre os dois países.

Nesta mesma época, as igrejas desenvolveram um discurso público de "direitos humanos". O trabalho do Cardeal D. Paulo Evaristo Arns e do pastor presbiteriano, Jaime Wright, é referência internacional ainda hoje sobre o período da ditadura militar. ${ }^{2} \mathrm{E}$ é muito difundida a ideia de uma igreja progressista no Brasil, com apoio ecumênico internacional. Mas, depois do Relatório Final da CNV, outras questões emergiram. Dom Helder Câmara (tão associado com a igreja progressista e secretário-geral da CNBB) recebeu informes regulares do serviço de inteligência britânico. Por quê? E, mais importante para este artigo, qual era o papel das igrejas britânicas em relação à ditadura militar, particularmente as duas igrejas nacionais comprometidas com o movimento ecumênico internacional: A Igreja da Inglaterra (Anglicana) e a Igreja da Escócia (Presbiteriana)? Este artigo pretende elaborar esta perspectiva eclesiástica.

Primeiro, queremos contextualizar o período histórico que foi o principal foco da CNV. Para tal, vamos fazer uma breve alusão aos Presidentes do Brasil e aos Primeiro Ministros do Reino Unido. Segundo, vamos esboçar (a partir dos arquivos relacionados à $\mathrm{CNV}$ ) por que o Relatório Final da CNV sugeriu que houve "colaboração britânica" com a tortura da ditadura militar. Além dos arquivos da $\mathrm{CNV}$, vamos lançar mão da pesquisa de João Roberto Martins Filho da Universidade Federal de São Carlos. ${ }^{3}$ Terceiro, vamos apresentar de forma preliminar os compromissos das igrejas (nacionais) britânicas com o discurso de direitos humanos. E, partindo dos acervos do parlamento britânico e dos documentos históricos do Ministério das Relações Exteriores do governo britânico, vamos apontar para diferenças de interesses no Brasil e para as preocupações das igrejas e da sociedade civil britânicas com o abuso de direitos humanos pela ditadura militar. Por outro, a preocupação do governo britânico em promover acordos de livre comércio com a ditadura

\footnotetext{
${ }^{2}$ ARNS, P. E., Brasil.

${ }^{3}$ MARTINS FILHO, J. R., Segredos de Estado.
} 
militar, sem prejudicar o seu compromisso com acordos internacionais de direitos humanos.

Devemos, ainda, sublinhar que esta é uma pesquisar preliminar. Nosso interesse no assunto foi despertado num evento no Instituto Brasil (Brazil Institute) da Kings College Londres, em 2016, quando o diretor Anthony Pereira notou que além da pesquisa feita pelo já mencionado João Roberto Martins Filho - quando ele passou um período de pesquisa em Londres no Instituto Brasil - não havia, ao menos que ele soubesse, pesquisa acerca dos muitos documentos da CNV por parte de pesquisadores, muito menos pesquisas que investigassem a suposta "colaboração britânica" com a tortura da ditadura militar. ${ }^{4}$

\section{1964 a 1985: Política de Estado, Presidentes e Primeiros-ministros}

"The police can deal as harshly as they like with émigré from Latin America... but not with visitors from [the UK]. It is an instinctive matter on both sides". ${ }^{5}$

O período da ditadura militar (1964-1985) é contestado na academia e sociedade brasileiras. ${ }^{6}$ Marcelo Ridente chama atenção para a importância de memórias e biografias neste exercício de rememoração. ${ }^{7}$ Ridente nota que em anos recentes - pós-redemocratização - o interesse no período da ditadura militar tem produzido uma ligeira mudança na memória do Brasil, em termos da ditadura. $\mathrm{O}$ golpe e a ditadura militar são frequentemente apresentados como um "golpe civil-militar" e como um "governo autoritário". ${ }^{8}$ Ridente

\footnotetext{
${ }^{4}$ Numa secção especial do periódico Bulletin of Latin American Research (2018) dedicado à Ditadura e seus legados no Brasil, os editores notam que "multi disciplinary research into the 21-year dictatorial period (1964-1984) has reached new levels of intensity. Scholars both within and outside Brazil are taking advantage of new resources generated by the CNV [...]. Many are also bringing new areas to light, reinvigorating long-standing debates, and challenging earlier interpretations and understandings". ATENCIO, R.; SCHNEIDER, N.; SCHNEIDER, A. M., Special Section on Dictatorship and Its Legacies in Brazil, p. 3.

5 "A polícia pode tratar o emigrante da América Latina tão duramente quanto quiser... mas não os visitantes [do Reino Unido]. É algo instintivo dos dois lados”. GREEN, G., Our Man in Havana, p. 155.

${ }^{6}$ Esta observação se estende à igreja brasileira também. Falaremos mais sobre isso na seção 3.

${ }^{7}$ RIDENTE, M., The debate over Military (or Civilian-Military?) Dictatorship in Brazil in Historiographical Context, p. 33.

${ }^{8}$ RIDENTE, M., The debate over Military (or Civilian-Military?) Dictatorship in Brazil in Historiographical Context, p. 35.
} 
fundamenta isso em publicações da década 1980, mas que ganham força ou consenso nos anos 1990 e 2000. Esta qualificação aponta para uma tendência no Brasil redemocratizado de revisitar relações civis-militares. ${ }^{9}$

As igrejas britânicas interpretaram o período de 1964-1985 como "golpe" e "ditadura militar". Já o governo britânico manteve uma interpretação diferente que oscilava entre "revolução" e "repressão". A questão da memória (interna à academia e sociedade brasileiras) não é menos importante para compreender a atuação e interação do governo e igrejas britânicas com o Brasil durante este período.

O marco temporal deste artigo prioriza o marco temporal do Relatório Final da Comissão Nacional da Verdade (CNV). A CNV foi criada pela Lei 12528/2011 e instituída em 16 de maio de 2012 com a finalidade de apurar graves violações de Direitos Humanos ocorridas entre 18 de setembro de 1946 e 5 de outubro de 1988. A CNV esclarece que, "no tocante ao marco temporal, o legislador elegeu o período entre 18 de setembro de 1946 e 5 de outubro de 1988, datas de promulgação de duas constituições democráticas". ${ }^{10}$ Também, o Relatório Final notou que, "a CNV concentrou seus esforços para o esclarecimento de graves violações de direitos humanos no período de 1964 a 1985, precisamente por haver identificado uma prática nesse sentido disseminada em larga escala pelo regime militar". ${ }^{11}$

Para a finalidade deste artigo, o marco temporal adotado compreende o período de 1964 a 1985. Deste modo, o artigo recorre a estudos de brazilianists, principalmente o clássico livro de Thomas Skidmore sobre a política do regime militar no Brasil, The Politics of Military Rule in Brazil, 1964-1985. ${ }^{12} \mathrm{O}$ livro de Thomas Skidmore e de outros brazilianists ofereceu as primeiras análises interpretativas do golpe e da ditadura militar que tiveram influência douradora nas subsequentes pesquisas (e reações da academia brasileira) sobre o período.

Skidmore fala de fases e ênfases diferentes durante a ditadura militar. É importante notar que o que Skidmore e outros brazilianists chamaram de golpe de 1964, os militares brasileiros e os diplomatas britânicos chamaram de "revolução". Esta memória contestada ainda está presente na academia, sociedade e igrejas brasileiras. Afinal, 1964 foi golpe ou revolução? O

\footnotetext{
${ }^{9}$ RIDENTE, M., The debate over Military (or Civilian-Military?) Dictatorship in Brazil in Historiographical Context, p. 37.

${ }^{10}$ COMISSÃO NACIONAL DA VERDADE, Relatório, $\S 76$, p. 41.

${ }^{11}$ COMISSÃO NACIONAL DA VERDADE, Relatório, § 77, p. 41.

${ }^{12}$ SKIDMORE, T., The Politics of Military Rule in Brazil.
} 
governo de Castelo Branco trouxe a "operação limpeza", ${ }^{13}$ que tinha como alvo partidos políticos da esquerda, movimentos sociais, universidades, militares pró-esquerda e a Igreja Católica. Costa e Silva assumiu a presidência em 1967 e priorizou a economia e um governo forte. ${ }^{14}$ Mas, o seu governo se tornou autoritário e a repressão provocou a emergência da guerrilha. ${ }^{15}$ Médici assumiu a presidência em 1969 e seu governo militar foi o mais repressor de todos. Ele liquidou a guerrilha ${ }^{16}$ e instalou a tortura regular como medida de guerra contra a população brasileira. ${ }^{17}$ Geisel assumiu a presidência em 1974 e é visto como o presidente da abertura no governo militar. Geisel era luterano, e apenas o segundo presidente não católico romano na história do Brasil. ${ }^{18}$ Figueiredo assumiu a presidência em 1979 e seguiu a política de abertura de Geisel, acrescentando a "liberalização" e a "negociação" como metas políticas do governo militar. ${ }^{19}$ A ditadura estava chegando ao fim e os sindicatos e a Igreja Católica Romana começaram a oferecer espaços para a sociedade civil sonhar com um governo democrático. Tancredo Neves foi eleito presidente em 1985, mas não chegou a assumir a presidência, falecendo antes da sua inauguração. Foi José Sarney que se tornou presidente em 1986, pondo fim aos governos militares.

No mesmo período (1964-1985), o Reino Unido passou por governos democráticos e primeiros-ministros diferentes. Harold Wilson foi primeiroministro de 1964 a 1970 e novamente de 1974 a 1976. Ele era do Labour Party (Partido Trabalhista). Edward Heath foi Primeiro-Ministro de 1970 a 1974 e era do Conservative Party (Partido Conservador). James Callaghan foi PrimeiroMinistro de 1976 a 1979 e assumiu o ofício quando Wilson se demitiu por ser do mesmo partido e não houve eleição geral. Em 1979, Margaret Thatcher foi eleita a primeira mulher no ofício de Primeiro-Ministro. Heath e Thatcher eram membros da Igreja da Inglaterra. Callaghan foi criado na Igreja Batista e Wilson era da Igreja Congregacional. Os dois primeiros-ministros do Partido Trabalhista vieram da tradição cristã britânica chamada "non-conformist". A

${ }^{13}$ SKIDMORE, T., The Politics of Military Rule in Brazil, p. 24.

${ }^{14}$ SKIDMORE, T., The Politics of Military Rule in Brazil, p. 68.

${ }^{15}$ SKIDMORE, T., The Politics of Military Rule in Brazil, p. 84.

${ }^{16}$ SKIDMORE, T., The Politics of Military Rule in Brazil, p. 117.

${ }^{17}$ SKIDMORE, T., The Politics of Military Rule in Brazil, p. 125.

${ }^{18}$ O primeiro Presidente protestante do Brasil foi João Fernandes Campos Café Filho (19541955). Ele era presbiteriano. Skidmore identifica Geisel como primeiro Presidente luterano. SKIDMORE, T., The Politics of Military Rule in Brazil, p. 161.

${ }^{19}$ SKIDMORE, T., The Politics of Military Rule in Brazil, p. 212. 
tradição "non-conformist" foi influenciada pela vontade de uma reforma mais radical na linha dos princípios presbiterianos no século 16 na Inglaterra. ${ }^{20} \mathrm{Ou}$ seja, não se conformaram com uma reforma limitada, a seu ver, da Igreja da Inglaterra. Não deveria ser necessário destacar que os primeiros-ministros do Partido Conservador pertenciam à igreja nacional.

João Roberto Martins Filho durante um período de estudo no Kings College, Londres, produziu uma pesquisa sobre a colaboração britânica com a ditadura militar relacionando os anos dos governos Wilson, Heath e Callaghan: Segredos de Estado: o governo britânico e a tortura no Brasil (1969-1976). Ele concluiu que em termos de "elaboração da política externa britânica [...] a postura do Foreign Office frente às denúncias de tortura no Brasil parece contrariar a tese de que a diplomacia do Labour é substancialmente diferente da do Conservative Party, principalmente no que tange aos direitos humanos". ${ }^{21}$ Wilson e Callaghan eram do Partido Trabalhista, Heath do Partido Conservador. Martins Filho não identificou uma diferença substancial em termos da política externa do governo britânico no período 1964 a 1985 . Ou seja, de acordo com Martins Filho, a política externa é conduzida pelo Foreign and Commonwelath Office (FCO) sem refletir necessariamente mudanças da esquerda ou da direita no governo britânico.

Uma observação pertinente do estudo de Martins Filho é uma carta do embaixador britânico relatando que a Embaixada considera o Presidente Ernesto Geisel como "um homem de religião e de princípios". ${ }^{22} \mathrm{Na}$ carta, o embaixador disse que o FCO tinha uma impressão favorável da pessoa e do preparo de Geisel. Esta observação é pertinente porque Geisel era protestante e percebe-se uma conflação de religião e política, na qual o governo britânico, através da sua embaixada no Brasil, manteve uma postura favorável a Geisel possibilitando a Harold Wilson estender um convite ao presidente do governo militar para fazer uma visita de Estado ao Reino Unido em 1976. Geisel foi recebido pelo Primeiro-Ministro James Callaghan (também do Partido Trabalhista).

Neste período, o Reino Unido tem governos democráticos de partidos de esquerda e de direita, com uma política externa que parecia funcionar

\footnotetext{
${ }^{20}$ HAZLETT, W. I. P., The Reformation in Britain and Ireland, p. 70.

${ }^{21}$ MARTINS FILHO, J. R., Segredos de Estado, p. 3. O texto utilizado nesta pesquisa foi uma versão mimeografada do mesmo. A pesquisa foi posteriormente publicada pela Editora Prisma, em 2017.

${ }^{22}$ MARTINS FILHO, J. R., Segredos de Estado, p. 84.
} 
independentemente de questões partidárias, bem como duas igrejas nacionais - a Igreja da Escócia e a Igreja da Inglaterra. O Reino Unido não possui uma constituição laica no modelo brasileiro e o papel dessas duas igrejas nacionais na contestação da política externa britânica no Brasil vai ser tratado no item 4. Por ora, é importante notar que "o princípio protestante" não deveria ser desprezado em relação às cortesias estendidas ao Presidente Geisel pelo governo britânico. Como veremos na próxima seção, o governo britânico já havia mudado sua interpretação da "revolução" de 1964 para classificá-la como "ditadura" devido ao aumento de documentos e evidências de tortura no Brasil (pelo menos em documentos internos, sob sigilo). Apesar desta nova interpretação, "o homem de religião e princípios" (Protestantes?) - Presidente Geisel - recebeu o convite para fazer uma visita de Estado ao Reino Unido. Ainda que o governo britânico soubesse das torturas no Brasil, tendo inclusive chamado o governo militar do Brasil de "ditadura" no mesmo período em que fez o convite.

\section{Tortura no Brasil e a "colaboração britânica"}

“Did you torture him? Captain Segura laughed, 'No, he doesn't belong to the torturable class'. 'I didn't know there were class distinctions in torture", ${ }^{23}$

Uma das revelações do Relatório Final da CNV, em seu capítulo 5, foi a confirmação de "antigos rumores" sobre a "colaboração britânica" com a ditadura militar. Especificamente, o Relatório Final aponta para esta colaboração na fundação e organização do Centro de Informações do Exterior (Ciex). "O próprio regulamento interno do Ciex (que até hoje permanece oculto) teve a contribuição de especialistas britânicos". ${ }^{24} \mathrm{O}$ Ciex foi criado pelo governo militar do Brasil em 1966 para a coleta e busca de informações sobre indivíduos e suas supostas atividades. De acordo com o Relatório Final, o Ciex foi responsável pela "aquisição de informações com o uso de meios encobertos, não raro clandestinos". ${ }^{25}$

\footnotetext{
23 “'Você o torturou? Capitão Segura riu, 'Não, ele não pertence às classes torturáveis'. 'Eu não sabia que havia distinções de classes na tortura'”. GREEN, G., Our Man in Havana, p. 155.

${ }^{24}$ COMISSÃO NACIONAL DA VERDADE, Relatório, § 54, p. 189.

${ }^{25}$ COMISSÃO NACIONAL DA VERDADE, Relatório, § 11, p. 179.
} 
Há tempo circulavam boatos sobre a "colaboração britânica" com a ditadura militar: "são antigos os rumores sobre uma possível colaboração entre o Ministério de Relações Exteriores (MRE) e a inteligência britânica. Em pelo menos um caso, eles foram abonados pela pesquisa historiográfica posterior" ${ }^{26}$ A fonte para esta afirmação do Relatório Final foi a visita de Maurice Oldfield, diplomata britânico, ao Brasil em 1960. Nos arquivos do MRE não existe nenhuma referência sobre a visita do Oldfield ao país. E durante a apuração da CNV o então primeiro-ministro do Reino Unido, David Cameron, recusou-se a responder aos pedidos de acesso aos arquivos do governo britânico para investigar os registros sobre a visita de Oldfield ao Brasil. ${ }^{27}$ A CNV se interessou pela visita de Oldfield e a falta de registros brasileiros e britânicos - porque três anos depois da visita dele ao Brasil, ele se tornou chefe do Serviço de Inteligência Britânica - MI6.

O Relatório Final destaca que futuramente poderiam surgir novas informações sobre esta visita e a relação entre os serviços de inteligência britânicos e brasileiros. Mas isto vai depender dos dois governos disponibilizarem acesso aos arquivos em sigilo e vai depender de pesquisa acadêmica contínua sobre a relação entre a ditadura militar e o governo britânico no período 1964 a 1985. Neste momento, baseado no Relatório Final, e os arquivos que o acompanha, continua a ser difícil provar ou confirmar de forma definitiva as suspeitas levantadas pela CNV sobre a "colaboração britânica" com a violação dos direitos humanos pelo governo militar no Brasil.

Apesar disso, o trabalho e publicação da CNV gerou interesse na mídia britânica. Em maio de 2014 - logo após a publicação do Relatório Final - a $B B C$ entrevistou Álvaro Caldas. Caldas foi membro do Partido Comunista e foi preso duas vezes pela ditadura militar (em 1970 quando ele ficou preso por dois anos, e novamente, em 1973 depois de ter desistido da política). $\mathrm{Na}$ entrevista dele com a $B B C$, ele relata que a segunda vez que foi preso no Rio de Janeiro foi torturado pelo "sistema inglês". No Brasil, a designação "sistema inglês" em relação às técnicas de tortura supostamente surgiu por causa da colaboração entre o Brasil e o Reino Unido. ${ }^{28}$ Em 20 horas de depoimento à CNV o Coronel Paulo Magalhães revelou que ele mesmo - e outros - viajou para o Reino Unido para aprender técnicas de tortura que não deixassem marcas físicas nos presos. Outros oficiais do exército confirmaram a

${ }^{26}$ COMISSÃO NACIONAL DA VERDADE, Relatório, § 54, p. 189.

${ }^{27}$ COMISSÃO NACIONAL DA VERDADE, Relatório, § 57, p. 190.

${ }^{28}$ BUCHANAN, E., How the UK taught Brazil's dictators interrogation techniques. 
pesquisadores da CNV a prática de visitar outros países para aprender técnicas de tortura, entre os quais Alemanha, França, Panamá e EUA. Porém, o Reino Unido era visto como o melhor país, com os melhores métodos. Também, o jornal britânico The Guardian, publicou matérias depois da publicação do Relatório Final citando o comentário do general Hugo de Andrade Abreu que disse que os militares brasileiros aprenderam com os ingleses. ${ }^{29}$ "Em fins de 1970 enviamos um grupo de oficiais do I Exército à Inglaterra para aprender o sistema inglês de interrogatório. O método consiste em colocar o prisioneiro em uma cela sem qualquer contato com o mundo exterior". ${ }^{30}$

Esta fala de Abreu coincide com a experiência de Caldas. Na segunda vez que ele foi preso em 1973, ele observou a limpeza e esterilidade da cela onde ele permaneceu sem noção de tempo e sem contato com o mundo exterior. Este tipo de técnica de tortura foi descrito no Compton Report de 1971. Este inquérito parlamentar britânico investigou as técnicas utilizadas pelas Forças Armadas britânicas durante o conflito com o Exército Republicano Irlandês (IRA). ${ }^{31}$ As falas de Caldas e Abreu na mídia britânica depois da publicação do Relatório Final e a documentação do próprio CNV confirmam os relatos do uso dessas técnicas no Brasil no período do governo militar. ${ }^{32} \mathrm{O}$ Compton Report forçou o Primeiro Ministro Edward Heath a se pronunciar no parlamento britânico: "no futuro, as técnicas que [Compton] examinou não serão mais usadas como auxílio em interrogatórios". ${ }^{33}$

Os documentos e arquivos pesquisados pela CNV revelam que a "colaboração britânica" do serviço de inteligência e do governo britânico não era apenas com a ditadura militar. Os britânicos também colaboraram com a sociedade civil e as igrejas brasileiras. É importante destacar que relações diplomáticas entre países contemplam diferentes agências e agentes de Estado, bem como diferentes atores da sociedade com interesses distintos. Os diplomatas britânicos ligados ao Foreign Office interpretaram a fase inicial do governo militar do Brasil em 1966 como "revolucionário". A leitura diplomática britânica inicial da "revolução" enfatizava o desejo do governo militar de superar a crise econômica do país e consolidar as novas

\footnotetext{
${ }^{29}$ WATTS, J.; ROCHA, J., Brazil president weeps as she unveils report on military dictatorship's abuses.

${ }^{30}$ COMISSÃO NACIONAL DA VERDADE, Relatório, § 18, p. 334.

${ }^{31}$ COMISSÃO NACIONAL DA VERDADE, Relatório, § 19, p. 334-335.

${ }^{32}$ COMISSÃO NACIONAL DA VERDADE, Relatório, § 20-21, p. 335-336.

${ }^{33}$ COBAIN, I., Cruel Britannia, p. 135.
} 
instituições em Brasília. ${ }^{34}$ Já na década 1970, a opinião diplomática britânica (em documentos internos sob sigilo) interpretava os governos militares do Brasil como "autoritários". Foi neste período que os diplomatas começaram a buscar mais informações sobre violações de direitos humanos e uso de tortura em prisioneiros políticos no Brasil. ${ }^{35}$ Em decorrência disso, os diplomatas expandiram seus contatos com a sociedade civil e as igrejas.

A Embaixada britânica no Brasil - como embaixadas de muitas outras nações - é o canal principal de relações entre os dois países. Ela age em muitas esferas e promove interesses britânicos neste país. Frequentemente, outros departamentos ou agências do governo britânico utilizam o canal da Embaixada para seus próprios interesses e até emprestam funcionários para a Embaixada. Apesar desta realidade, documentos do FCO mostram que, independentemente da Embaixada, o serviço de inteligência operava não oficialmente no Brasil. Esta observação é diferente de afirmar que o serviço de inteligência britânica não operava no Brasil. Um dos principais trabalhos do sistema de inteligência britânica no país foi a divulgação dos relatórios ou informes do Information Research Department (IRD). Em maio de 1969, o FCO descreveu o objetivo do IRD no Brasil: "to help Brazil discreetly in the field of counter-subversion and to influence people in government, trade unions, schools, universities, armed forces, women's organisations, Church and Press". ${ }^{36}$ Esta ajuda com o contraterrorismo e a ampliação da esfera de influência britânica no país focaram em personagens do governo, sindicatos, escolas, universidades, forças armadas, grupos de mulheres, igrejas e mídia. Apesar de ocorrer durante o período da "guerra fria", o IRD divulgou seus relatórios e informes para grupos da esquerda, direita e centro em termos políticos. O FCO nota a diversidade de leitores dos relatórios e informes do IRD: "several Brazilian archbishops (including Dom Helder Camara) and bishops are IRD readers as well as parish priests, Jesuit teachers of secondary schools, and Jesuit organisations concerned with social welfare". ${ }^{37}$ Esta diversidade - com foco nas igrejas - revela como o FCO compreendeu as

\footnotetext{
${ }^{34} \mathrm{FCO} 95 / 491$.

${ }^{35} \mathrm{FCO} 7 / 2205$. FCO 7/3048.

36 “Ajudar o Brasil discretamente no campo da contra-subversão e influenciar pessoas do governo, sindicatos, escolas, universidades, forças armadas, organizações de mulheres, Igreja e Imprensa" (FCO 95/491).

37 "Muitos arcebispos brasileiros (incluindo Dom Helder Câmara) e bispos são leitores do $I R D$ tanto quanto padres de paróquia, professores jesuítas de escolas, e organizações sociais jesuítas" (FCO 95/491).
} 
igrejas como instituições importantes no combate ao terrorismo e como agente de influência no Brasil. Por exemplo, o trabalho do IRD ajudou um professor jesuíta a combater o terrorismo, especificamente interpretado como opiniões comunistas entre estudantes. Num outro caso no Estado de Pernambuco, o IRD ajudou um padre a combater as ligas camponesas. ${ }^{38}$

Não é o escopo deste trabalho, mas a citação do nome do Dom Helder Câmara pelo $F C O$ como leitor dos relatórios e informes do IRD chama atenção e merece um breve comentário. Dom Helder Câmara foi arcebispo de Recife e Olinda, assumindo a arquidiocese em 1964. Antes disso participou no Vaticano II e foi secretário-geral da Conferência Nacional dos Bispos do Brasil (CNBB). Ele leu os informes do $I R D$ quando estava à frente da arquidiocese. Câmara exerceu grande influência entres os bispos brasileiros e em 1975 estava ao lado de Dom Paulo Evaristo Arns em São Paulo na ocasião do "ato ecumênico" por Vladimir Herzog, jornalista morto pela tortura da ditadura militar. Na época, o Presidente Geisel - um homem de religião e princípios protestantes - tentou dissuadir o Cardeal Arns de realizar o "ato ecumênico". $\mathrm{O}$ ato se tornou um marco histórico na luta das igrejas e sociedade civil contra a ditadura militar. ${ }^{39}$

O Relatório Final da CNV e os documentos e arquivos disponibilizados ao público poderiam permitir novas pesquisas sobre Dom Helder Câmara, arcebispo tão associado à "igreja progressista", à "opção pelos pobres" da igreja brasileira e à teologia da libertação na América Latina. Do ponto de visto deste artigo - mas fora do seu escopo - interessaria reavaliar a relação de Dom Helder Câmara com os britânicos. Não devemos esquecer que foi a visita dele ao Reino Unido em 1969 que instigou a carta aberta de grupos estudantis e igrejas do movimento ecumênico sobre a situação no Brasil. O Student Christian Movement (SCM) [Movimento Estudantil Universitário] e o British Council of Churches (BCC) [Conselho Nacional de Igrejas Britânicas] denunciaram a cumplicidade da ditadura militar no assassinato de um auxiliar de Dom Helder Câmara e nos ataques à sua casa pastoral. ${ }^{40}$ Porém, até a publicação do Relatório Final da CNV e a disponibilização dos documentos e arquivos, era pouco conhecida e comentada a relação do Dom Helder Câmara com o serviço de inteligência britânica e diplomatas britânicos.

\footnotetext{
${ }^{38}$ FCO 95/491.

${ }^{39}$ ROCHA, Z. (Org.)., Helder, O Dom.

${ }^{40}$ MARTINS FILHO, J. R., Segredos de Estado, p. 21.
} 
Por outro lado, é importante notar que, pelo menos a partir de 1975, João Roberto Martins Filho aponta que a CNBB informava aos diplomatas britânicos sobre violações de direitos humanos pela ditadura militar e tortura de prisioneiros políticos. ${ }^{41}$ Ou seja, um dos colaboradores com o serviço de inteligência britânica e diplomatas britânicos foi a igreja católica no Brasil, pelo menos durante a tentativa do governo inglês em levantar informações e relatos sobre o uso de tortura pela ditadura. Vale ressaltar que esta mudança de política do governo do Reino Unido diante da crescente pressão das igrejas e da sociedade britânica ocorreu durante a Presidência de Geisel - o homem de religião e princípios protestantes.

\section{Os Direitos humanos e as igrejas britânicas}

"Dear Mr. Wormold, surely you recognise there are people who expect to be tortured and [others] who would be outraged by the idea" ${ }^{42}$

Houve opiniões que contestaram a posição e interpretação do governo britânico diante da ditadura militar no Brasil. Entre 1964 e 1985, a ação secreta do serviço de inteligência e a ação discreta dos diplomatas britânicos no Brasil não gerou consenso entre a população do Reio Unido, inclusive entre parlamentares. Na década de 1970, Peter Archer, membro do parlamento e do Partido Trabalhista fez uma pergunta sobre o Brasil no parlamento britânico. Esta década marcou o momento em que o governo britânico começou a reclassificar a "revolução" e "governo autoritário" do Brasil como "golpe" e "ditadura". Archer era conhecido pelo seu trabalho em defesa de direitos humanos e reconhecido (até pelo Partido Conservador) por seu socialismo-cristão. Preocupado com as notícias do Brasil sobre a prisão de brasileiros que discordaram das políticas do regime militar, Archer fez sua pergunta sobre a intenção do Primeiro Ministro de fazer uma visita de Estado ao Brasil:

$\S$ Q3. Mr. Peter Archer asked the Prime Minister if he will seek to make an official visit to Brazil.

$\S$ The Prime Minister: I have at present no plans to do so.

${ }^{41}$ MARTINS FILHO, J. R., Segredos de Estado, p. 148.

42 "Meu querido Senhor Wormworld, certamente você reconhece que existem pessoas que esperam ser torturadas (e outras) que estariam lívidas com tal ideia". GREEN, G., Our Man in Havana, p. 155. 
§Mr. Archer: Will the Prime Minister find another method of indicating to the Brazilian Government public disquiet in this country at the nearextinction of the Indian minority and the number of people imprisoned in Brazil simply because they disagree with the Government, or does the right hon. Gentleman accept no responsibility for international human rights obligations?

$\S$ The Prime Minister: The Brazilian Government must be well aware of the reports which have appeared in the Press in this country and the attitude which has been taken on them, but it is a matter for which the Brazilian Government themselves must answer. ${ }^{43}$

Peter Archer era Queens Counsel (QC), importante distinção na sua profissão de advogado. E como cristão-socialista era pacifista e trabalhava na defesa de direitos humanos. A pergunta de Peter Archer ao Primeiro Ministro foi feita no contexto de matérias publicadas pela mídia britânica sobre a violação de direitos humanos no Brasil. As publicações foram influenciadas pelo trabalho da Amnesty International, Oxfam, Student Christian Movement e o British Council of Churches. Diante disso, a sociedade civil britânica - e certos parlamentares tais como Peter Archer - expressava inquietação sobre relatos de mais uma ditadura latino-americana violando os direitos humanos dos seus cidadãos. $\mathrm{O}$ caso que ganhou mais espaço, atenção e preocupação no Reino Unido foi a ditadura de Pinochet. Devido aos relatos e críticas em relação ao Chile, o Parlamento e a sociedade britânica ficaram mais sensibilizados sobre outros regimes ditatoriais na América Latina. ${ }^{44}$

A pergunta de Peter Archer vinculou política externa britânica com a promoção de direitos humanos. Ele fundamentou a pergunta na Declaração Universal de Direitos Humanos (1948) e as subsequentes convenções e estruturas de direito internacional. O Primeiro-Ministro foi evasivo na sua resposta sobre a responsabilidade do seu governo em reforçar ou policiar o novo paradigma de direito internacional. Ele ofereceu uma resposta que reconhecia a soberania de outros governos, ou seja, o princípio da nãointervenção em questões domésticas de outros países, neste caso as do Brasil.

A pergunta de Archer no parlamento não foi uma pergunta isolada. Fazia parte de um movimento das igrejas e sociedade civil em relação aos

${ }^{43}$ HOUSE OF COMMONS HANSARD, Commons Chamber. 01 Dec. 1970, vol 807, column 1077.

${ }^{44}$ As ditaduras militares da América Latina não foram todos iguais. Para um panorama geral das ditaduras militares na América Latina: COMBLIN, J., A Ideologia da Segurança Nacional. 
relatos sobre tortura no Brasil. Em 1972, o Catholic Institute of International Relations escreveu uma carta formal para o ministro do FCO, Alec DouglasHome, para apelar ao governo britânico a investigar o tratamento (tortura) de prisioneiros políticos no Brasil. ${ }^{45}$ Os documentos e arquivos disponibilizados pelo CNV demonstram que Douglas-Home foi orientado por um funcionário do $F C O$ a responder que o governo inglês apoiava a Declaração Universal dos Direito Humanos, mas ao mesmo tempo respeitava a soberania de outros governos.

Atualmente, é fácil esquecer que o discurso de direitos humanos é relativamente novo. Ele se tornou tão importante para constituições, governos, direito internacional, igrejas e sociedade civil que quase todos fazem questão de fazer referência ao conceito (ainda que haja contestações sobre seu uso, compreensão e parâmetros). Samuel Moyn nota que artigos acadêmicos com o título "direitos humanos" aparecem pela primeira vez (nos EUA) apenas na década de 1990 (mais de 40 anos depois da Declaração Universal de Direitos Humanos). ${ }^{46}$ Obviamente estes artigos estão fora do marco temporal deste texto. Porém, a observação dele é interessante em termos de contemplar o Relatório Final da CNV e a contestação do período da ditadura militar (19641985) na academia e sociedade brasileiras. Apesar de o tema dos direitos humanos ser uma referência quase universal ainda há grupos no Brasil que contestam (ou desconfiam) tanto dos direitos humanos quanto da memória da ditadura militar, principalmente entre as igrejas. ${ }^{47}$

É diferente no Reino Unido. O discurso dos direitos humanos é amplamente usado pelas igrejas e sociedade civil. As razões para isso são que os direitos humanos são compreendidos como fruto dos labores cristãos no século XX. O livro do Samuel Myon, Christian Human Rights, trata extensivamente esta questão. Em termos das igrejas nacionais do Reino Unido - Igreja da Inglaterra e Igreja da Escócia - elas foram profundamente influenciadas pela Conferência Igreja e Sociedade do Conselho Mundial de

\footnotetext{
${ }^{45}$ FCO 7/2205. FCO 7/3048.

${ }^{46}$ MOYN, S., Christian Human Rights, p. 101.

${ }^{47}$ Esta é uma questão sensível, principalmente porque em tempos recentes (depois da década 1990 citado por Samuel Myon) há várias publicações teológicas no Brasil sobre direitos humanos. Também, como já mencionado neste artigo, igrejas brasileiras participaram ativamente na resistência à ditadura militar e empregaram um discurso de defesa de direitos humanos. Porém, há expressivos exemplos de igrejas que apenas compreendem direitos humanos em termos de "liberdade religiosa" e colocam em oposição "direitos humanos" e "direitos religiosos" na rubrica de "liberdade religiosa".
} 
Igrejas em 1966. Em sua história da Church of Scotland Overseas Council no período 1947 a 1972, David Lyon nota que a Igreja da Escócia e o British Council of Churches adotaram políticas missionárias - num período decolonial - na linha dos direitos humanos. ${ }^{48}$

No Brasil, a publicação do livro Brasil: Nunca Mais pela arquidiocese de São Paulo relata, entre outras coisas, o compromisso do movimento ecumênico com os direitos humanos na segunda parte do século 20. Apesar do livro frequentemente ser confundido como obra de Dom Paulo Evaristo Arns, Brasil: Nunca Mais, é um relato de um projeto ecumênico da Arquidiocese de São Paulo em prol de direitos humanos durante a ditadura militar. O projeto ecumênico envolveu Jaime Wright - pastor presbiteriano - e foi apoiado (inclusive financeiramente) pelo CMI. Philip Potter, que foi secretário-geral do Conselho Mundial de Igrejas (CMI), escreveu o prefácio do livro: "Quando o Conselho Mundial de Igrejas foi oficialmente inaugurado em 1948, seus membros fizeram uma clara declaração sobre direitos humanos". ${ }^{49}$ Nota-se que o CMI foi fundado no mesmo ano da Declaração Universal de Direitos Humanos: 1948. A Igreja da Escócia e a Igreja da Inglaterra foram membros fundadores do CMI, e, depois de Unitatis Redintegratio do Vaticano II, a Igreja Católica Romana começou a participar como "observador" dos trabalhos e reuniões do CMI.

Na Assembleia do CMI em 1975, Potter relata que, "apelos foram feitos às autoridades brasileiras e ao mundo sobre o que estava acontecendo no Brasil". ${ }^{50}$ E novamente, em 1984, o Comitê Central do CMI fez uma declaração em apoio à nova convenção internacional sobre a tortura sob o título, "Convenção contra a Tortura e outro Tratamento ou Castigo Cruel, Desumano ou Degradante".

Estamos hoje sob o julgamento de Deus, porquanto em nossa geração a escuridão, fraude e desumanidade da câmara de tortura tornaram-se uma realidade mais difundida e atroz [...] Nenhuma prática humana é tão abominável, e nem tão universalmente condenada. No entanto, as torturas física e mental e outras formas de tratamento cruel e desumano estão agora sendo aplicadas sistematicamente em muitos países. ${ }^{51}$

\footnotetext{
${ }^{48}$ LYON, D. H. S., In Pursuit of a Vision, p. 236.

${ }^{49}$ ARNS, P. E., Brasil, p. 15.

${ }^{50}$ ARNS, P. E., Brasil, p. 16

${ }^{51}$ ARNS, P. E., Brasil, p. 294.
} 
Estas ações do movimento ecumênico foram feitas antes da publicação do livro, Brasil: Nunca Mais. Tanto a Igreja da Escócia quanto a Igreja da Inglaterra participaram como membros (e a Igreja Católica Romana como observadora) da Assembleia de 1975 e do Comitê Central de 1984 do CMI. O pano de fundo da declaração de 1984 foi a situação dos direitos humanos na América Latina, inclusive no Brasil. O CMI estava ciente do empenho ecumênico no Brasil, e na América Latina em geral, a favor dos direitos humanos desde 1979, esforços esses que integraram o livro Brasil: Nunca Mais.

Em 1974, o Arcebispo da Cantuária, Michael Ramsey, líder da Igreja da Inglaterra, fez uma visita oficial ao Brasil. Ramsey visitou Argentina, Colômbia, Chile e Brasil durante uma viagem de 19 dias. Em vários países se deparou com a situação de direitos humanos violados. No Brasil, ele foi recebido pelo Presidente Geisel e aproveitou a reunião para perguntar diretamente ao Presidente sobre o desaparecimento de uma professora. ${ }^{52}$ Ramsey sabia do desaparecimento dela pela informação repassada pelo Cardeal do Rio de Janeiro, Dom Eugênio Sales durante seu encontro. Depois da reunião entre Ramsey e Sales, ele repassou a informação aos diplomatas britânicos no Brasil. Os diplomatas foram cautelosos diante da informação apresentada pelo arcebispo britânico. Eles lamentaram que pudessem fazer muito pouco no caso da professora e aconselharam o arcebispo britânico a não intervir.

Por isso, Ramsey decidiu levar a informação do Cardeal Sales diretamente ao Presidente Geisel durante o encontro pessoal. A Igreja da Inglaterra é uma igreja nacional. Ela tem uma relação privilegiada em assuntos de Estado e com o governo. Porém, ela mantém autonomia diante de contextos pastorais. Ramsey - com a compreensão de direitos humanos como missão da igreja usou desta autonomia pastoral para perguntar ao Presidente Geisel sobre o desaparecimento da professora. Igreja e Estado nem sempre seguem as mesmas políticas externas, nem em contextos onde a igreja é nacional e tem uma relação privilegiada com o Estado e o governo. Ademais, à luz de documentos do próprio governo britânico disponibilizados pela $\mathrm{CNV}$, vários diplomatas britânicos não queriam pressionar a ditadura militar sobre desaparecimentos, tortura e violação de direitos humanos. Os diplomatas acreditaram que uma tentativa de intervenção britânica na política doméstica do Brasil causaria mais dificuldades e repressão. ${ }^{53}$

\footnotetext{
${ }^{52}$ MARTINS FILHO, J. R., Segredos de Estado, p. 103.

${ }^{53}$ FCO 95/491.
} 
Por sua vez, as igrejas britânicas, especialmente as duas igrejas nacionais da Inglaterra e da Escócia, foram influenciadas por questões além da política externa do Reino Unido. O movimento ecumênico e a reformulação do conceito de missão da igreja como promoção de direitos humanos foi fundamental na segunda parte do século XX. Além disso, a abertura de relações e colaboração entre igrejas protestantes e católicas romanas depois do Vaticano II foram importantes. Dom Helder Câmara foi recebido pelas igrejas protestantes no Reino Unido em 1969. Do mesmo modo, o arcebispo protestante, Michael Ramsey, foi recebido pela Igreja Católica Romana no Brasil em 1974. Tanto a Igreja da Escócia quanto a Igreja da Inglaterra comprometeram-se com um forte discurso a favor dos direitos humanos neste período sob a influência do movimento ecumênico. Este compromisso com os direitos humanos, interpretado como missão da igreja, em alguns momentos colocou as igrejas em oposição à política externa do governo britânico e até mesmo com os conselhos de diplomatas do próprio governo em questões de direitos humanos e tortura no Brasil.

Como vimos, em 1976, o Presidente Geisel - o homem de religião e princípios protestantes - fez uma visita de Estado ao Reino Unido. Depois da visita, Ernest Perry do Partido Trabalhista perguntou ao primeiro-ministro acerca da visita e sobre a questão de direitos humanos no Brasil:

$\S$ Mr. Ernest G. Perry asked the Prime Minister whether he discussed the question of human rights with President Geisel of Brazil during his recent State visit to this country.

$\S$ The Prime Minister: Yes. In the course of my discussions with President Geisel I made clear to him the strong feelings that exist in this country on the question of human rights. ${ }^{54}$

Interessante desta interação no parlamento britânico é que Perry está fazendo o questionamento para o líder do seu próprio partido. A resposta de Callaghan é diferente da resposta do primeiro-ministro, Edward Health, em 1970. As perguntas de Archer e Perry são bastante parecidas, ainda que separadas no tempo por 6 anos, e focam na questão da violação dos direitos humanos no Brasil. A resposta do Callaghan pode ser diferente da de Heath por duas razões principais. Ou Callaghan estava ciente da crescente oposição britânica na sociedade civil e nas igrejas contra a violação dos direitos humanos, ou ele estava ciente das notícias sobre a tortura de prisioneiros políticos no

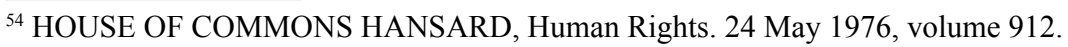


Brasil (ou uma combinação das duas). De qualquer modo, Callaghan viu-se obrigado a conversar com o Presidente Geisel sobre essas violações durante a sua visita de Estado ao Reino Unido. João Roberto Martins Filho cita que "a 24 de março de 1976, Callaghan recebeu, já como primeiro-ministro, sua primeira denúncia de tortura no Brasil. Encaminhada por um parlamentar de seu partido, Arthur Latham". ${ }^{55}$ Como já notado, a década de 1970 viu uma mudança de interpretação do governo britânico sobre a ditadura militar e a violação de direitos humanos no Brasil. Já em 1976, o governo britânico sentiu-se suficientemente ciente da situação no país - através do trabalho das igrejas e da sociedade civil - para poder interferir publicamente em questões domésticas - na soberania de outro governo - onde e quando os direitos humanos estivessem sendo violados.

\section{Igreja, livre comércio e direitos humanos}

"It is an instinctive matter on both sides. Catholics are more torturable than Protestants". ${ }^{56}$

Em 1810, Portugal e Grã-Bretanha assinaram o "Tratado de Comércio e Navegação", às vezes chamado de "Tratado do Rio Janeiro". Este tratado formalizou os interesses britânicos no Brasil (e em outros territórios portugueses) e norteou os futuros interesses do Reino Unido na América Latina. O comércio internacional e de investimento (trade and investment), conhecido hoje em dia como livre comércio, era o interesse principal dos britânicos visando manter poder preeminente na região no século XIX. O livro de Victor Bulmer-Thomas, Britain and Latin America, traz reflexões sobre estes interesses comerciais do Reino Unido no Brasil, incluindo outros países da América Latina. Bulmer-Thomas nota no seu prefácio do livro que os britânicos eram acostumados a ser o poder econômico e político dominante na América Latina, como em outras regiões do mundo, durante o século $19 .{ }^{57}$ No século 20, os EUA superaram o Reino Unido em termos de poder dominante na região. Mas, ainda que com uma influência agora periférica, o Reino Unido manteve o mesmo interesse: livre comércio.

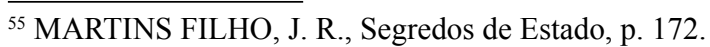

56 "É um assunto instintivo dos dois lados. Católicos são mais torturáveis que Protestantes". GREEN, G., Our Man in Havana, p. 155.

${ }^{57}$ BULMER-THOMAS, V., Prefácio, p. ix.
} 
Com o Brasil o governo britânico sempre privilegiou relações comerciais. De 1810 até os dias de hoje o Reino Unido sempre focou na questão de livre comércio com o Brasil. A relação econômica continuou a ser privilegiada em assuntos de Estado. Embora o Brasil tenha vivenciado governos e sistemas constitucionais variados desde 1810, o governo britânico sempre insistiu que qualquer relação com o Brasil e o seu governo fosse baseada na promoção de acordos comerciais para beneficiar a economia britânica. Esta política externa continuou durante a ditadura militar.

Como já foi apontado, em 1968, a Rainha Elizabeth II fez uma visita de Estado ao Brasil em plena ditadura militar. Ela foi recebida pelo Presidente Costa e Silva. No período da ditadura militar nenhum primeiro-ministro visitou Brasil (foi apenas em 2001 que Tony Blair se tornou o primeiro primeiro-ministro a fazer uma visita oficial ao país). No parlamento britânico, poucos dias depois da visita de Estado, Gordon Oakes do Partido Trabalhista perguntou à secretária para o comércio britânico, Gwyneth Dunwoody (do mesmo partido dele) sobre o Brasil:

$\S$ Mr. Oakes asked the President of the Board of Trade whether any special arrangements are being made to increase British exports to Brazil.

§Mrs. Gwyneth Dunwoody: Brazil is one of the important targets in Latin America and British exporters are being especially encouraged to seek orders there. My right hon. Friend will be opening a major British Industrial Exhibition in Sao Paulo next March. Very large loans and lines of credit have recently been made available by British banks with the support of E.C.G.D. for exports to Brazil. ${ }^{58}$

Como se pode notar, a pergunta não era sobre direitos humanos. A visita da Rainha Elizabeth II ao Brasil priorizou acordos econômicos favoráveis a empresas e a economia britânicas. Esta perspectiva sobre política externa e livre comércio ajuda a explicar certa reserva dos diplomatas ingleses em relação às notícias sobre a violação dos direitos humanos pela ditadura militar. A diplomacia britânica, pelo menos até aquele momento, não havia desenvolvido um discurso de direitos humanos em termos de relações entre governos. O vínculo entre direitos humanos, livre comércio e política externa ainda não havia sido estabelecido. A história demonstra que o interesse britânico no Brasil sempre foi a questão da economia e do livre comércio.

${ }^{58}$ HOUSE OF COMMONS HANSARD, Latin America. 27 Nov. 1968, volume 774. 
Apesar do livro de Bulmer-Thomas indicar o lugar periférico do Reino Unido em relação ao Brasil e à América Latina no século 20, é surpreendente perceber, através do relatório da $\mathrm{CNV}$, o quanto a diplomacia britânica foi ativa no Brasil, um país onde o Reino Unido há tempos havia perdido sua influência. E é mais surpreendente ainda que em questões de economia e livre comércio a exportação de técnicas de tortura fosse considerada trade and investment (comércio internacional e investimento). A "colaboração britânica" em termos do "sistema inglês" a as operações dos serviços de inteligência britânicas no Brasil durante a ditadura militar poderiam simplesmente ter a explicação de que o governo do Reino Unido, à luz das suas prioridades econômicas e comerciais, viu uma oportunidade em vender inteligência, estratégia e equipamento militar britânico para um governo que combatia o grande inimigo do mundo ocidental daquela época: o comunismo.

$\mathrm{O}$ interesse das igrejas não priorizava o livre comércio, e sim direitos humanos. John Nurser documenta o trabalho das igrejas em prol da Declaração Universal de Direitos Humanos no seu livro For all Peoples and All Nations: "as igrejas protestantes do movimento ecumênico contribuíram significativamente [...] às Nações Unidas e à sua 'alma' de direitos humanos (Tradução nossa)". ${ }^{59}$ Nurser pesquisa a aliança transatlântica protestante na redação da Declaração Universal dos Direitos Humanos. Samuel Moyn concorda com a pesquisa de Nurser sobre esta influência protestante na redação da Declaração Universal. O norte-americano Fred Nolde é uma personagem principal desta história ${ }^{60}$ como também, John Foster Dulles. Do lado britânico John Mackay e Robert Mackie da Escócia, e William Paton, William Temple e George Bell da Inglaterra. ${ }^{61}$ Em outras palavras, no período em que o governo britânico tentava reiniciar relações com o Brasil através de visitas de Estado para promover acordos comerciais, e na mesma época em que o Brasil vivenciou uma ditadura militar com crescente documentação disponível sobre a violação de direitos humanos, as igrejas nacionais do Reino Unido se esforçaram para criar um discurso internacional de direitos humanos. E tal discurso contrariava a política externa de livre comércio do próprio governo do Reino Unido naquela época. ${ }^{62}$

\footnotetext{
${ }^{59}$ NURSER, J., For all Peoples and All Nations, p. 172.

${ }^{60}$ NURSER, J., For all Peoples and All Nations, p. 27.

${ }^{61}$ NURSER, J., For all Peoples and All Nations, p. 52.

${ }^{62} \mathrm{O}$ governo britânico ainda não desenvolveu um ethical Foreign policy com a qual Robin Cook tanto sonhava nos primeiros anos do governo do Primeiro-Ministro Tony Blair.
} 
As igrejas nacionais britânicas - Igreja da Inglaterra e Igreja da Escócia priorizavam a promoção dos direitos humanos no Brasil. O governo britânico priorizava acordos de livre comércio. Porém, a política externa da ambos igrejas e governo britânicos - compreenderam seu modo de agir com e no Brasil como uma forma de difundir o desenvolvimento sustentável que ia ajudar o Brasil a superar os problemas associados com a pobreza. Do mesmo modo que a ditadura militar falava de "milagre econômico" para tirar o Brasil da pobreza, os britânicos conduziram políticas externas no país com o objetivo de melhorar a vida do povo brasileiro. Os métodos foram simplesmente diferentes. As igrejas britânicas escolheram direitos humanos. O governo britânico escolheu livre comércio. A ditadura militar escolheu repressão e tortura. As preferências dos britânicos não impediram nem o governo nem as igrejas de interagir com a ditadura militar. E ciente das observações de Bulmer-Thomas a ação dos britânicos é apenas um rodapé na história da ditadura militar.

\section{Conclusão}

João Roberto Martins Filho termina sua pesquisa dos documentos da CNV notando:

Surpreendentemente, a investigação revelou não apenas a recusa do Foreign Office em aceitar a realidade da tortura no Brasil, mas o segredo maior da relação entre os dois países no período 1969-1976: a participação direta da Grã-Bretanha na construção do sistema de tortura, nunca suspeitada pela própria Anistia Internacional. ${ }^{63}$

Martins Filho analisou documentos da CNV, do FCO e da Anistia Internacional e traçou o discurso emergente de violação de direitos humanos pelo governo militar no Brasil. Ele aponta que o $F C O$ e o governo britânico recusam a admitir publicamente a tortura e violação de direitos humanos documentados no período da ditadura militar (1964 a 1985). Apenas em meados da década de 1970, a interpretação britânica sobre o "golpe" e a "ditadura militar" começou a mudar. Porém, desde 1969 (um ano depois da visita de Estado da Rainha Elizabeth II ao Brasil), a mídia britânica, as igrejas nacionais e a sociedade civil pressionavam o governo sobre a tortura

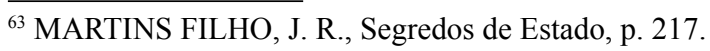


e a violação de direitos humanos no Brasil. Além disso, no início da década 1970, parlamentares britânicos já faziam questionamentos no parlamento para o governo e primeiro-ministro sobre a situação de direitos humanos no Brasil. Martins Filho, e o Relatório Final da CNV, notam o silêncio até hoje do governo do Reino Unido em comentar sobre uma possível "colaboração britânica" com a ditadura militar entre 1964 e 1985.

O Relatório Final da CNV e os documentos e arquivos disponibilizados pela apuração da CNV mostram que o serviço de inteligência e os diplomatas britânicos colaboraram com um número de indivíduos e setores amplos durante a ditadura militar. Por exemplo, os relatórios e informes do IRD circulavam quase "livremente" entre figuras da ditadura militar, e entre outras lideranças da direita, do centro e da esquerda em termos políticos. O Reino Unido procurava assegurar sua influência no Brasil - num período em que ele já havia se tornado periférico na América Latina suplantado pela supremacia e hegemonia dos EUA na região - para melhorar suas exportações. A economia foi uma prioridade não só para a ditadura. Também foi uma prioridade para governos sucessivos do Reino Unido. Os acordos de livre comércio foram vistos como motor principal das relações externas entre o Reino Unido e o Brasil. Aliás, sempre foram desde 1810.

Outro foco nas relações entre o Brasil e o Reino Unido aparece no relatório da CNV e no estudo do Martins Filho. É a perspectiva trabalhada neste artigo: as igrejas. Nem toda a população brasileira concordava com a ditadura militar. Também nem toda a população britânica concordava com a prioridade de livre comércio em relações exteriores, especificamente com o Brasil. As igrejas brasileiras (através de lideranças tais como Dom Helder Câmara, Dom Paulo Evaristo Arns e Jaime Wright) interagiam com os diplomatas e igrejas britânicas e o movimento ecumênico. As igrejas britânicas, através do seu esforço de interpretar a missão da igreja como a promoção de direitos humanos, apoiaram a visita do Dom Helder Câmara ao Reino Unido, e questionavam diretamente o Presidente de uma ditadura militar sobre direitos humanos. Estas mesmas igrejas e o movimento ecumênico pressionavam parlamentares e ministros do governo britânico sobre torturas e violação de direitos humanos no Brasil. Esta política externa das igrejas nacionais - a Igreja da Escócia e a Igreja da Inglaterra - permitiu um espaço de diálogo e troca de informações sobre tortura e violação de direitos humanos com diplomatas, parlamentares e a sociedade civil do Reino Unido. De certa forma, as igrejas ajudaram a contribuir para uma política externa britânica 
mais atenta aos direitos humanos e que posteriormente ia vincular a promoção de livre comércio com direitos humanos.

O Relatório Final da CNV abre muitas perguntas e perspectivas para futuras pesquisas sobre a relação entre o Brasil e o Reino Unido entre 1964 e $1985 .{ }^{64}$ Há muito material disponível que ainda não foi pesquisado, trabalhado e publicado. Seguramente as pesquisas futuras vão destacar relações entre governos, diplomatas e serviços de inteligência. É onde aparecem as suspeitas e dúvidas, sem conclusões definitivas nos documentos e arquivos disponibilizados pela CNV. Mas, há outros possíveis focos. As igrejas são uma dessas possibilidades. Neste artigo nos propusemos investigar a colaboração do governo britânico, através do seu Ministério das Relações Exteriores e de seus serviços de inteligência, com o regime militar brasileiro. Paralelamente, pesquisou o papel das igrejas nacionais britânicas (da Inglaterra e Escócia), bem como da imprensa e da sociedade civil, quanto à pressão exercida sobre o governo por um posicionamento firme frente às denúncias de tortura, violações dos direitos humanos e prisões contra dissidentes políticos em curso no Brasil. A pressão exercida pelas igrejas britânicas foi municiada pela intensa troca de informações com igrejas e lideranças eclesiásticas brasileiras no âmbito do movimento ecumênico. Neste caso, sua política externa de promoção de direitos humanos, desenvolvida no movimento ecumênico do século 20, oferece outro ângulo para se olhar para as relações Igreja-Estado e as relações internacionais.

\section{Referências bibliográficas}

ATENCIO, R.; SCHNEIDER, N.; SCHNEIDER, A. M. Special Section on Dictatorship and Its Legacies in Brazil: Introduction. Bulletin of Latin American Research, v. 37, n. 1, p. 3-4, Jan. 2018. Disponível em: <https:// doi.org/10.1111/blar.12520>. Acesso em: 06 jun. 2018.

ARNS, P. E. Brasil: Nunca Mais. Petrópolis: Vozes, 1985.

BUCHANAN, E. How the UK taught Brazil's dictators interrogation techniques. BBC News, 30 may 2014. Disponível em: <http://www.bbc. co.uk/news/magazine-27625540>. Acesso em: 06 jun. 2016.

\footnotetext{
${ }^{64} \mathrm{O}$ foco da CNV não é o Reino Unido e sua relação com o Brasil. O foco dela é apurar graves violações de Direitos Humanos ocorridas entre 18 de setembro de 1946 e 5 de outubro de 1988 no Brasil.
} 
BULMER-THOMAS, V. Prefácio. In: BULMER-THOMAS, V. (Org.). Britain and Latin America: a changing relationship. Cambridge: Cambridge University Press, 1989. p. ix-xii.

COBAIN, I. Cruel Britannia: a secret history of torture. Londres: Portobelo, 2013.

COMBLin, J. A Ideologia da Segurança Nacional. Rio de Janeiro: Civilização Brasileira, 1978.

COMISSÃO NACIONAL DA VERDADE. Relatório / Comissão Nacional da Verdade. Brasília: CNV, 2014. v.1. Disponível em: $<$ http://cnv. memoriasreveladas.gov.br/images/pdf/relatorio/volume_1_digital.pdf $>$. Acesso em: 06 jun. 2016.

FOREIGN and Commonwealth Office. FCO 7/2205. FCO 7/3048. National Archives in UK. Disponível em: <http://cnv.memoriasreveladas. gov.br/images/documentos/Capitulo5/Nota\%2039\%20-\%20\%20 00092_002223_2014_33\%20-\%20National\%20Archives\%20FCO\%207\%20 2205\%20FCO\%207\%203048\%20(UK).pdf>. Acesso em: 06 jun. 2016.

FOREIGN and Commonwealth Office. FCO 95/941. National Archives in UK. Disponível em: <http://cnv.memoriasreveladas.gov.br/images/ documentos/Capitulo5/Nota\%2039\%20-\%2000092_002229_2014_19\%20 -\%20National $\% 20$ Archives\%20FCO\%2095\%20491\%20(UK).pdf>. Acesso em: 06 jun. 2016.

GREEN, G. Our Man in Havana. London: Vintage Books, 2001.

HAZLETT, W. I. P. The Reformation in Britain and Ireland. London: T \& T Clark, 2005.

HOUSE OF COMMONS HANSARD. Commons Chamber. 01 Dec. 1970, volume 807, column 1077. Disponível em: <https://hansard.parliament.uk/ Commons/1970-12-01/debates/91d9519a-8bdc-4f46-a869-6cd27f0cfdb0/ CommonsChamber $>$. Acesso em: 06 jun. 2016.

HOUSE OF COMMONS HANSARD. Human Rights. 24 May. 1976, volume 912. Disponível em: <https://hansard.parliament.uk/commons/1976-05-24/ debates/cc15307e-d682-4117-a619-df69297bde9a/HumanRights>. Acesso em: 06 jun. 2016.

HOUSE OF COMMONS HANSARD. Latin America. 27 Nov. 1968, volume 774. Disponível em: <https://hansard.parliament.uk/Commons/1968-11-27/ 
debates/28d1d713-99fd-42ce-9f5b-f5a339956db1/LatinAmerica>. Acesso em: 06 jun. 2016.

LYON, D. H. S. In Pursuit of a Vision. Edinburgh: Saint Andrew Press, 1998. MARTINS FILHO, J. R. Segredos de Estado: o governo britânico e a tortura no Brasil (1969-1976). São Carlos: mimeografia não publicada, 2015.

McGEOCH, G. G. Para inglês ver? Relações Igreja-Estado entre o Brasil e o Reino Unido (1964-1985). In: CONGRESSO INTERNACIONAL DA FACUldADE EST, 3., 2016, São Leopoldo. Anais do Congresso Internacional da Faculdades EST. São Leopoldo: EST, 2016. p. 470-481. Disponível em: <file://C:/Users/User/Downloads/792-2563-1-PB\%20(2). pdf $>$. Acesso em: 06 jun. 2017.

MOYN, S. Christian Human Rights. Philadelphia: University of Pennsylvania Press, 2015.

NURSER, J. For all Peoples and All Nations. Geneva: WCC Publications, 2005.

RIDENTE, M. The debate over Military (or Civilian-Military?) Dictatorship in Brazil in Historiographical Context. Bulletin of Latin American Research, v. 37. n. 1. p. 33-42, Jan. 2018.

ROCHA, Z. (Org.). Helder: o Dom. Petrópolis: Vozes, 1999.

SKIDMORE, T. The Politics of Military Rule in Brazil: 1964-1985. New York: Oxford University Press, 1988.

WATTS, J.; ROCHA, J. Brazil president weeps as she unveils report on military dictatorship's abuses. The Guardian, 10 dec. 2014. Disponível em: $<$ http://www.theguardian.com/world/2014/dec/10/brazil-president-weepsreport-military-dictatorship-abuses $>$. Acesso em: 06 jun. 2016.

\section{Graham Gerald McGeoch}

Doutor em Teologia e Ciências da Religião pela Universidade de Glasgow, Escócia Docente na Faculdade Unida de Vitória Vitória / ES - Brasil E-mail: graham@fuv.edu.br 


\section{Wanderley Pereira da Rosa}

Doutor em Teologia pela Pontifícia Universidade Católica do Rio de Janeiro

Docente de História do Cristianismo na Faculdade Unida de Vitória Vitória / ES - Brasil

E-mail: wanderley@fuv.edu.br

Recebido em: 30/07/2020

Aprovado em: 16/11/2020 